\title{
EVALUATION OF BUSINESS MODELS OF URBAN IOT- APPLICATIONS FOR A MEDIUM SIZED CITY
}

\author{
Ferdinand Fischer ${ }^{1}$ and Birgit Schenk ${ }^{2}$
}

DOI: $10.24989 /$ ocg.338.31

\begin{abstract}
Digitalization of the public sector is being driven by a number of factors. In particular, the concept of "Smart Cities" has become an important driver of this development. This relies heavily on an intelligent infrastructure including the Internet of Things (IoT). But does it make sense for small and medium-sized municipalities to develop this? Is it justified to invest in IoT? (How) can a mediumsized city benefit from it? This paper presents the application of an evaluation scheme for business models of urban IoT applications to answer these questions. The research question focuses on how best practices of urban IoT applications in general and in particular can be evaluated. In order to establish a concrete practical reference we evaluated ten chosen IoT applications for the German city of Herrenberg.
\end{abstract}

\section{Smart Cities and the Case of medium-sized Cities}

The urbanization of the world has reached an astonishing pace. In Germany, around $77 \%$ of the population already live in densely populated areas. This means that our communities are facing new challenges in all urban areas such as urban development and housing, security, transport and pollution, economic growth, social interaction, food and health etc. Resources are already scarce, from raw materials to drinking water and clean air. Our living spaces have become smaller. As a result, growing cities place more complex and dynamic demands on government and administration than traditional communities. Local governments will have to manage this growth and it will put severe strain on municipal finances [1]. Therefore, the concept of smart City is important and city planning gets more and more critical [17].

According to a meta study by the International Telecommunication Union [15], the center of a smart city is the use of modern information and communication technologies (ICT), with the help of which the quality of life in the city, the efficiency of administrative action and the competitiveness should be increased. The Internet of Things plays a central role in this [10]. As part of a large-scale ranking of medium-sized smart cities, GIFFINGER et al. [8] define six properties that intelligent networked cities share: Smart Economy, Smart People, Smart Governance, Smart Mobility, Smart Environment, Smart Living. COHEN [2] has further developed this classification and illustrated it in the so-called Smart City Wheel.

But cities of today face increasing challenges when it comes to providing public services with innovative technologies. Local authorities often have great difficulty in driving forward the urgently needed developments towards a Smart City. Tight budgets and a lack of skilled workers also make it

\footnotetext{
${ }^{1}$ Hochschule für Öffentliche Verwaltung und Finanzen, Ludwigsburg

${ }^{2}$ Hochschule für Öffentliche Verwaltung und Finanzen, Ludwigsburg
} 
more difficult to invest in innovative municipal IoT applications and benefit from them in the long term [7].

This is where the concept of business models comes in handy. It offers the opportunity to evaluate new business ideas in detail, to review existing activities, and to then make coordinated changes to business activities, strategies and structures through systematic simplification [16].

But does it make sense for small and medium-sized municipalities to develop this? Is it justified to invest in IoT? (How) Can a medium-sized city benefit from it?

Therefore, best-practice business models of selected municipal IoT applications were systematically analyzed and described to be able to evaluate them, answering the question:

Which IoT applications are suitable for a medium-sized city?

This paper presents the application of an evaluation scheme for business models of urban IoT applications to answer this question.

\section{Background}

\subsection{IoT in the Public Sector}

FLÜGge/Fromm [6] classify IoT in the public sector as (I) the Public Internet of Things and (II) the Internet of Public Things.

They speak of Public Internet of Things when the state acts both as a regulator and a shaper, firstly by setting and enforcing binding rules secondly by providing the necessary public IoT infrastructure for consumer and industrial IoT.

The Internet of Public Things includes activities of the public sector when the public sector itself becomes a user of IoT. Things under state sovereignty can also be digitally identified or networked, which has great potential for efficiency and effectiveness of administrative action. Sensors that record, for example, the structural condition of public buildings, environmental parameters in public spaces or flood levels are already in use today. This also includes the area of services of general interest, where the state or local authorities have a guarantee responsibility. Even though tasks such as supply or public transport are often performed by the private sector, this area can also be assigned to the Internet of Public Things because of its great importance for the public.

For this paper applications of the Internet of Public Things were investigated.

\subsection{Business Models}

The business model approach is a management concept for increasing success [16]. A business model shows the logical relationships of a business activity in a simplified form [9]. It therefore depicts the essence of the business activity in order to present even complex interrelationships in a comprehensible way [16]. 
The business model perspective is useful in three respects: new business ideas can be evaluated in a well-founded way, previous entrepreneurial activities can be put to the test and existing business activities can be changed in a coordinated manner if necessary [16].

The concept of the business model had its breakthrough in the era of the New Economy. With the success of the Internet, fundamentally new opportunities for value creation arose, and the value proposition increasingly became the focus of entrepreneurial activity. Companies operated in a highly complex and volatile market, and the management of business models provided an answer to how companies could succeed in such an uncertain environment [16].

The situation in which the start-ups of the New Economy found themselves has certain parallels with the current situation of local government. In the world of VUCA, they are looking for clues as to how a transformation to a Smart City can succeed in the long term. Technological developments lead to new ways in which local governments can create value. New business models are needed to benefit from this in the long term [3].

OSTERWALDER [12] created a framework that covers the four areas of a business (also based on the balanced scorecard approach): the product, the customer interface, infrastructure management and finance. He divided these areas into nine components, which OSTERWALDER/PIGNEUR [11] illustrated clearly in the so-called Business Model Canvas. For non-profit or government organizations, the authors recommend expanding the nine components to include social and ecological considerations. The so-called Business Model Canvas for non-profit organizations is created. Therefore, this approach was chosen for the present paper (see figure 1).

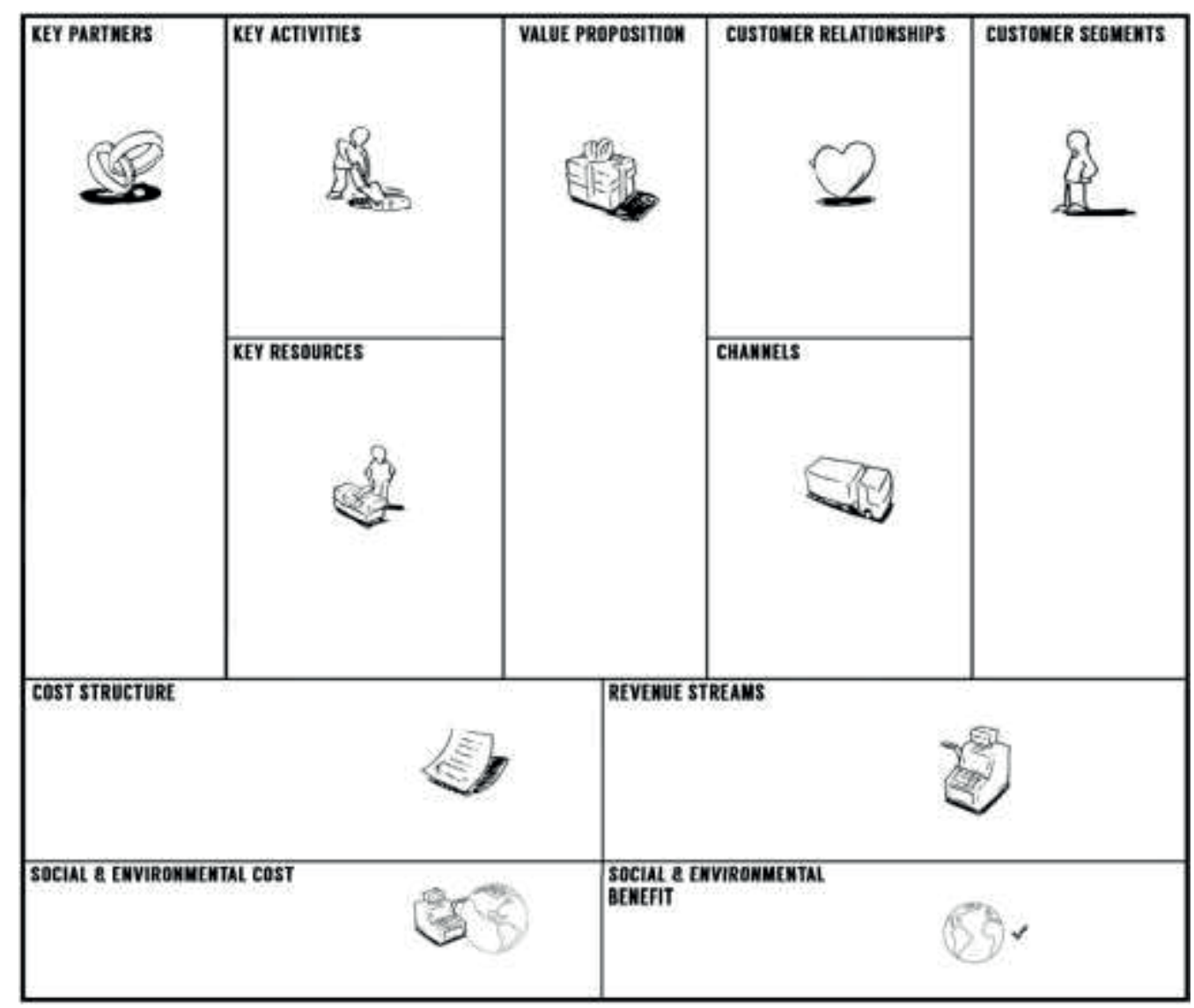

Figure 1: The Business Model Canvas for Non-Profit-Organizations by Osterwalder/Pigneur [11] 


\subsection{Business Model Evaluation}

To evaluate business models of a smart City DÍAZ-DÍAZ/MuÑOZ/PÉREZ-GONZÁLEZ [4] presented the so-called Business Model Evaluation Tool for Smart Cities, which is the basis of this work. This clearly structured evaluation scheme is based on the business model approach by OSTERWALDER/PIGNEUR [11]. With the help of this evaluation matrix it is possible to evaluate the collected and described business models and to transfer them to the city of Herrenberg. A points system allows the comparability of the business models. Consisting of six categories, each of which can be evaluated with up to five points, the following parameters are assessed: cost structure, revenue streams, social and environmental costs, social and environmental benefits, value proposition and the customer segment.

The following formula is used to calculate the respective Value of the Business Model:

$$
\begin{gathered}
\mathrm{VBM}=(\mathrm{CE}+\mathrm{RE}-\mathrm{SEC}+\mathrm{SEB}+\mathrm{VP}) * \mathrm{CS} \\
\mathrm{VBM}=\text { Value of the Business Model } \\
\mathrm{CE}=\text { Cost Structure } \\
\mathrm{RE}=\text { Revenue Streams } \\
\mathrm{SEC}=\text { Social and Environmental Costs } \\
\mathrm{SEB}=\text { Social and Environmental Benefits } \\
\mathrm{VP}=\text { Value Proposition } \\
\mathrm{CS}=\text { Customer Segment }
\end{gathered}
$$

There are a total of 29 questions, which can be found in detail in the sample evaluation matrix in the appendix.

\section{Methodology}

In order to define the scientific frame of reference, an in-depth literature search was completed on approaches of the Business Model Canvas for municipalities or with reference to IoT applications. Looking for best practices a broad literature search was conducted to find suitable municipal IoT applications. The search was limited to the European area and to cities with less than 200,000 inhabitants in order to avoid too great structural differences in the evaluation of the business models for a medium-sized city. Another criterion for the selection of IoT applications was that they should be established services (no pilot projects) in order to obtain reliable information.

In order to establish a concrete practical reference, the found business model canvas is related to Herrenberg, a medium-sized town in Baden-Württemberg.

The city of Herrenberg is a small medium-sized city (31,500 inhabitants) in the suburban area of the Stuttgart metropolitan region, which has already started activities in the field of Smart City and launched the first municipal IoT applications. For this purpose, a city-owned LoRaWan (Long Range Wide Area Network) has been set up, which will in future network sensors throughout the city. Already established are the large-scale collection of municipal waste containers or sensor-based support for winter road maintenance services. There is a consensus within the city administration that further applications should follow.

The following municipal IoT applications were selected: 
(1) Bad Hersfeld, Germany: Smart City Cockpit, sensor-based parking space management, citizens app for noise measurement, integrated street lightning

(2) Darmstadt, Germany: Web app for traffic information, Green phase prediction service, Open traffic data

(3) Santander, Spain:

Smart street lighting, Gardens and parks irrigation with IoT, Water supply with IoT

To obtain information about the business models of the selected IoT applications, in addition to an in-depth literature search, two telephone interviews with experts were conducted using partly standardized guidelines. The interview partners were recruited from "Smart Cities" known in Germany: Bad Hersfeld and Darmstadt.

Santander served as a European example. Here, extensive scientific literature could be referred to.

In order to evaluate the business models for the city of Herrenberg, the current state of the city in relation to the examined IoT applications was firstly determined. For this purpose, an expert interview was conducted with the head of the Office for Technology, Environment, Green of the City of Herrenberg. This was also a partially standardized guideline interview.

\section{Results}

The results can be seen in the following table:

\begin{tabular}{|c|c|c|c|c|c|c|c|c|}
\hline & IoT-Application & CE & RE & SEC & SEB & $\mathbf{V P}$ & CS & VBM \\
\hline \multirow{4}{*}{ 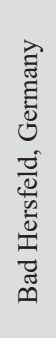 } & Smart City Cockpit & - & - & 0 & 3,5 & 2 & 5 & 27,5 \\
\hline & Sensor-based parking space management & - & 0 & -1 & 2,5 & 4 & 5 & 27,5 \\
\hline & Citizens app for noise measurement & 3 & 0 & 0 & 2 & 3,5 & 3 & 25,5 \\
\hline & Integrated street lightning & 3 & 0 & 0 & 2 & 4 & 2 & 18 \\
\hline \multirow{3}{*}{ 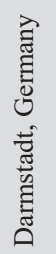 } & Web app for traffic information & 0 & - & 0 & 3 & 3 & 5 & 30 \\
\hline & Green phase prediction service & - & - & 0 & 2,5 & 3,5 & 5 & 30 \\
\hline & Open traffic data & 0 & 0 & 0 & 2,5 & 2 & 5 & 22,5 \\
\hline \multirow{3}{*}{ 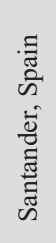 } & Smart street lighting & 2 & 0 & 0 & 1,5 & 3 & 5 & 32,5 \\
\hline & Gardens and parks irrigation with IoT & 2 & 0 & 0 & 1,5 & 2,5 & 5 & 30 \\
\hline & Water supply with IoT & 1 & 0 & 0 & 1,5 & 2,5 & 5 & 25 \\
\hline
\end{tabular}

Table 1: Results of the application of the Business Model Evaluation Tool by DíAZ-DíAZ/Mũ̃oz/PÉREZ-GONZÁLEZ [4] 
For those business models for which no information on their cost structure could be collected, a sensitivity analysis was carried out under $\mathrm{VBM}=0$. It was determined how high the costs of the services could be, in order to ensure that the business models continue to have a positive value. As shown in table 2 , a critical value of -5.5 and -6 was found for the cost structure. These values are both below the minimum possible value of the cost structure within the valuation scheme $(\min =-5)$. This means that even with a cost maximum of the IoT applications (in relation to the valuation scheme) the value of their business model (CBM) would be positive and the service would therefore be fundamentally recommendable. A balancing factor is therefore not necessary.

\begin{tabular}{|l|c|}
\hline IoT-Application & Critical value of CE (under VBM = 0) \\
\hline Smart City Cockpit & $-5,5$ \\
\hline Sensor-based parking space management & $-5,5$ \\
\hline Web app for traffic information & -6 \\
\hline Green phase prediction service & -6 \\
\hline
\end{tabular}

Table 2: Critical values of $\mathrm{CE}$ under $\mathrm{VBM}=0$

The results are presented using an example of one of the selected IoT applications - the Smart City Cockpit of Bad Hersfeld [14]: The Hessian district town of Bad Hersfeld has already set up several municipal IoT applications. This makes it a prime example of how smaller towns can also benefit from the "Smart City" concept. The city administration is pursuing a holistic approach in the transformation to a Smart City: all urban data and Smart City projects in the city are bundled via a central platform. The so-called Smart City Cockpit is a web-based application that attractively visualizes all existing city data and provides a quick overview of the city's condition. In addition, the Smart City projects in the city are to be brought closer to the population in order to create a basis for citizen participation.

In addition to informing the population, visitor groups and the city administration about the current state of the city, the value proposition also includes the provision of historical sensor data in open and machine-readable CSV format. The Smart City Cockpit can thus be regarded as an open data portal of the Internet of Things in the City. There are no access restrictions and there are no fees to be paid. 


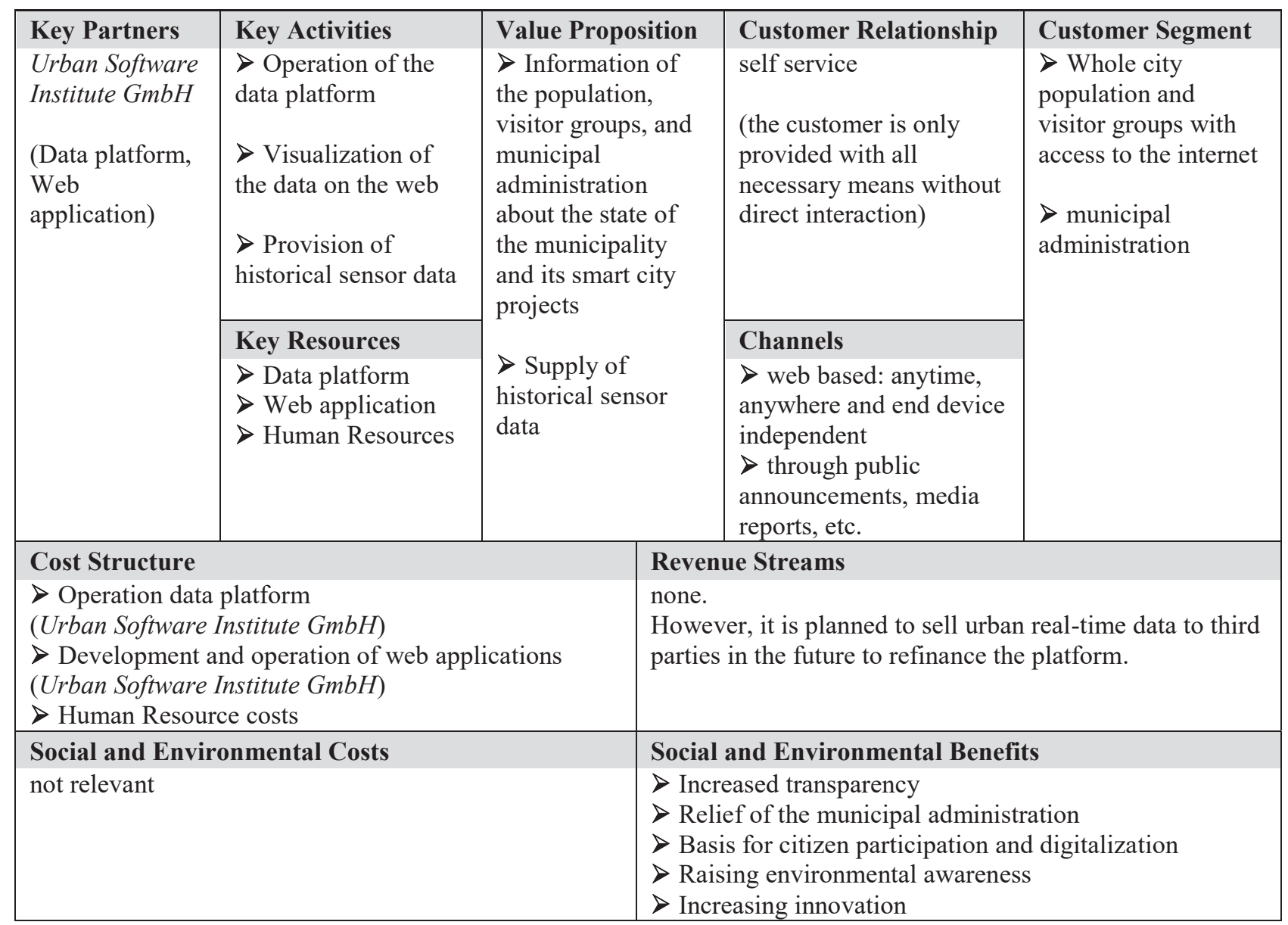

Figure 2: Business Model Canvas of the Smart City Cockpit, Bad Hersfeld [5]

The cockpit can be accessed online by anyone, regardless of location, time or terminal device, so the business model appeals to the population and visitors with Internet access as well as local companies or the city administration itself. The customer relationship is based on the principle of self-service, as the customer is only provided with all necessary resources without direct interaction.

The parameters of the cost structure and the sources of income are evaluated in the evaluation matrix by comparison with the traditional service provision. However, such a comparison does not exist in the case of the Smart City Cockpit, since only the use of IoT makes such an application possible in the first place. Cost structure and sources of income are therefore not assessable.

Revenues are not generated by the Smart City Cockpit. In principle, however, it would be conceivable to make the use of valuable real-time data available to private companies for a fee.

Considerable social and ecological costs - i.e. negative effects on the city's strategic goals - would not arise if the service were introduced in Herrenberg. 0 points are awarded.

Rather, the service would have social and ecological advantages, i.e. it would serve strategic goals of the city of Herrenberg: The city would come closer to its goal of becoming a "Bürgerkommune" (high citizen participation) by informing its residents comprehensively about the activities of the Smart City and thus create the basis for impulses from the population. Especially in the context of Smart City, the participation of all stakeholders is crucial for the success of the transformation [7]. 
The introduction of the Smart City Cockpit would also help to achieve Herrenberg's mobility goals by publishing information on parking space occupancy: The population could obtain online information about the current parking situation before entering the city. This would help to reduce the search for parking spaces, which on average accounts for about $30 \%$ of all inner city traffic [13]. Air and noise pollution as well as congestion should be reduced.

The cockpit would contribute to environmental protection. By informing the population about environmental data such as particulate matter or noise pollution in the city, the environmental awareness of the inhabitants can be raised and their behavior positively influenced.

It is also expected that the position of Herrenberg as a business location will be slightly strengthened. The open-data offer of the cockpit would increase Herrenberg's innovative strength. Open data can be used by private (hobby) developers to create new innovative applications. Overall, the social and ecological benefits are rated with 3.5 points.

The value proposition of the Smart City Cockpit can be evaluated as follows: The service would fulfil the information needs of the municipal administration and the inhabitants of Herrenberg. Their quality of life would not be directly increased by the bundling of data. In Bad Hersfeld the service is used by its inhabitants. There are no reliable reasons to assume that this could be different in Herrenberg. Both the quality and the price of the service compared to other alternatives are not comparable to any other application and therefore cannot be evaluated. A total of 2 points are awarded for the value proposition.

When assessing the customer segment, it depends on how many people in the city would benefit or suffer from the service. Due to the wide range of available data and open access, the service is beneficial for over $50 \%$ of the city's population. The Herrenberg population would not be harmed by the service. The customer segment is rated with 5 points.

By using the valuation formula, the value of the business model (VBM) for the Smart City Cockpit from Bad Hersfeld is 27.5.

$$
\begin{aligned}
& \mathrm{VBM}=(\mathrm{CE}+\mathrm{RE}-\mathrm{SEC}+\mathrm{SEB}+\mathrm{VP}) * \mathrm{CS} \\
& \mathrm{VBM}=(\mathrm{X}+\mathrm{X}-0+3,5+2) * 5 \\
& \mathrm{VBM}=27,5
\end{aligned}
$$

\section{Discussion}

To return to our hypotheses put forward in the introductory section, we can now clarify them. The application of the Business Model Evaluation Tool for Smart Cities by DíAZ-DÍAz/MuÑOz/PÉREZGONZÁLEZ [4] resulted in a positive rating (between 18 and 32.5 points) for all ten business models examined. This means that all examined IoT applications could be recommended in principle to the city of Herrenberg. In the following, however, the results of the individual business models will be discussed critically and limitations will be pointed out. 


\subsection{Recommendations for the City of Herrenberg}

In order to answer the question of which IoT applications are suitable for a medium-sized city using the example of the city of Herrenberg, Germany, we have categorized the results into recommendable, recommendable but not urgent and not recommendable. The assessment of the urgency is a personal judgment of the authors based on a critical appraisal of the results. This is shown in the following table:

\begin{tabular}{|c|c|c|c|c|}
\hline & IoT-Application & VBM & Remarks & Recommendable? \\
\hline \multirow{4}{*}{ 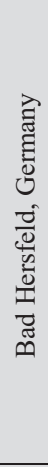 } & Smart City Cockpit & 27,5 & Very good rating is justified. & Yes. \\
\hline & $\begin{array}{l}\text { Sensor-based parking } \\
\text { space management }\end{array}$ & 27,5 & The issue is sensitive to urban policy. & No. \\
\hline & $\begin{array}{l}\text { Citizens app for noise } \\
\text { measurement }\end{array}$ & 25,5 & $\begin{array}{l}\text { Data quality cannot be guaranteed, } \\
\text { risk of distortion of noise mapping by } \\
\text { biased users }\end{array}$ & No. \\
\hline & $\begin{array}{l}\text { Integrated street } \\
\text { lighting }\end{array}$ & 18 & $\begin{array}{l}\text { Not suitable for city-wide use, in } \\
\text { Herrenberg no restriction of the user } \\
\text { group possible. }\end{array}$ & No. \\
\hline \multirow{3}{*}{ 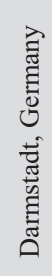 } & $\begin{array}{l}\text { Web app for traffic } \\
\text { information }\end{array}$ & 30 & Very good rating is justified. & Yes. \\
\hline & $\begin{array}{l}\text { Green phase } \\
\text { prediction service }\end{array}$ & 30 & $\begin{array}{c}\text { Application too young. Has to be } \\
\text { observed. }\end{array}$ & $\begin{array}{l}\text { Yes, but not } \\
\text { urgent. }\end{array}$ \\
\hline & Open traffic data & 22,5 & Good is rating justified. & Yes. \\
\hline \multirow{3}{*}{ 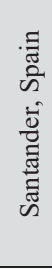 } & Smart street lighting & 32,5 & Very good rating is justified. & Yes. \\
\hline & $\begin{array}{l}\text { Gardens and parks } \\
\text { irrigation with IoT }\end{array}$ & 30 & $\begin{array}{l}\text { Good rating is justified. Application is } \\
\text { not yet necessary. }\end{array}$ & $\begin{array}{l}\text { Yes, but not } \\
\text { urgent. }\end{array}$ \\
\hline & Water supply with IoT & 25 & $\begin{array}{l}\text { Good rating is justified. Application is } \\
\text { not yet necessary. }\end{array}$ & $\begin{array}{l}\text { Yes, but not } \\
\text { urgent. }\end{array}$ \\
\hline
\end{tabular}

Table 3: Recommendations to the City of Herrenberg, Germany [5]

\subsection{General limitations}

In most cases, meaningful results have been achieved by applying the Business Model Evaluation Tool for Smart Cities by DíAZ-DÍAZ/MuÑoz/PÉREZ-GonZÁlEZ [4]. However, in some cases restrictions had to be accepted: The evaluation scheme only provides for a comparison with traditional service provision in order to assess the parameters of cost structure and revenue sources. For business models of municipal IoT applications that pursue a previously unknown value proposition and thus do not include traditional service provision, these parameters were therefore not included in the evaluation. In some cases it was also found that neither the existing literature nor discussions with municipal experts provided reliable information on the cost structure. This may also lead to distortions in the assessment. 


\section{Conclusions}

At the very beginning there was the question of whether it is sensible and justified for small and medium-sized communities to invest in the Internet of Things, and also the question of whether and how they can benefit from it. The application of the Business Model Evaluation Tool for Smart Cities by DíAZ-DíAZ/MuÑOZ/PÉREZ-GONZÁLEZ [4] has shown that these questions can be answered for a medium-sized city like Herrenberg. As the ten selected and evaluated IoT applications show, it is worthwhile for small and medium-sized as well as for large municipalities. Whether and how small and medium-sized municipalities should join forces to drive forward the development of a Smart City, possibly in a network, would be a question that could tie in with this work. This is because cost structures can change advantageously with a scale-up and the benefits could be further increased.

\section{References}

[1] CHOURABI, H. et al., Understanding Smart Cities: An Integrative Framework, in: 45th Hawaii International Conference on System Sciences, 2012, p. 2289-2297.

[2] COHEN, B., The Smartest Cities In The World 2015, 2014, https://www.fastcompany.com/ 3038818/the-smartest-cities-in-the-world-2015-methodology, last access 22.02.2020.

[3] DÍAZ-DÍAZ, R., MUÑOZ, L. and PÉREZ-GONZÁLEZ, D., Business model analysis of public services operating in the smart city ecosystem. The case of SmartSantander, in: Future Generation Computer Systems 76, 2017.

[4] DÍAZ-DÍAZ, R., MUÑOZ, L. and PÉREZ-GONZÁLEZ, D., The Business Model Evaluation Tool for Smart Cities: Application to SmartSantander Use Cases, in: Energies 10(3), 2017.

[5] FISCHER, F., Geschäftsmodelle ausgewählter kommunaler IoT-Anwendungen und deren Bewertung für die Stadt Herrenberg, Ludwigsburg, 2020.

[6] FLÜGGE, M. and FROMM, J. (ed.), Public IoT - Das Internet der Dinge im öffentlichen Raum, 2016, https://cdn0.scrvt.com/fokus/36c5e4909a46af02/982714594f78/WP_Public_ Internet_of_Things_web.pdf, last access 22.02.2020.

[7] GASSMANN, O., BÖHM, J. and PALMIÉ, M., Smart City. Innovationen für die vernetzte Stadt - Geschäftsmodelle und Management, München, 2018.

[8] GIFFINGER, R. et al., Smart cities - Ranking of European medium-sized cities, 2007, http://www.smart-cities.eu/download/smart_cities_final_report.pdf, last access 22.02.2020.

[9] GRÖSSER, S., Definition: Geschäftsmodell, 2018, https://wirtschaftslexikon.gabler.de/ definition/geschaeftsmodell-52275, last access 22.02.2020.

[10] HALLER, S., Smart Cities and Regions: Die digitale Transformation in der Stadtentwicklung und E-Government, in: Stember, Jürgen et al. (ed.): Handbuch E-Government, Technikinduzierte Verwaltungsentwicklung, Wiesbaden, 2019.

[11] OSTERWALDER, A. and PIGNEUR, Y., Business Model Generation: A Handbook for Visionaries, Game Changers, and Challengers, Hoboken/NJ, 2010. 
[12] OSTERWALDER, A., The Business Model Ontology. A Proposition in a Design Science Approach, University of Lausanne, 2004.

[13] SHOUP, D., Cruising for parking, in: Transport Policy 13, 2006, S. 480.

[14] Smart City Cockpit, https://badhersfeld.urbanpulse.de, last access 22.02.2020.

[15] TELECOMMUNICATION STANDARDIZATION SECTOR OF ITU (ITU-T): Smart sustainable cities: An analysis of definitions, 10/2014, https://www.itu.int/en/ITU-T/focusgroups/ssc/Documents/Approved_Deliverables/TR-Definitions.docx, last access 22.02.2020.

[16] WIRTZ, B. W., Business Model Management, Wiesbaden, 2018.

[17] ZYGIARIS, S., Smart City Reference Model: Assisting Planners to Conceptualize the Building of Smart City Innovation Ecosystems, in: J Knowl Econ, vol. 2(1), 2011. 